\title{
Política de educação especial e o atendimento educacional especializado no estado de Santa Catarina
}

Valéria Becher Trentin*

\section{Resumo}

A Política de Educação Especial na Perspectiva da Educação Inclusiva (2008) vem se manifestando nos documentos que orientam a educação inclusiva nos estados brasileiros de maneiras diversas. Nesse sentido, o presente artigo tem por objetivo identificar as expressōes da Política de Educação Especial na Perspectiva da Educação Inclusiva (2008) na Política de Educação Especial de SC (2009), no que tange o Atendimento Educacional Especializado (AEE). De abordagem qualitativa, foi utilizada a análise documental em que toma como fonte de dados os documentos que norteiam a educação inclusiva no âmbito internacional, nacional e estadual. Constatou-se que a Política de Educação Especial de SC ao instituir o Serviço de Atendimento Educacional Especializado (SAEDE), mesmo com denominação diferenciada, apresenta similaridade com o AEE no objetivo e no público-alvo. A Política de Educação Especial de SC em seu texto evidencia a proposta de efetivação da educação inclusiva, em que a Educação Especial deixa de ser um sistema paralelo com abordagem assistencialista e passa a ser uma modalidade que perpassa todos os níveis, etapas e modalidades de ensino, sem substituí-los, ofertando os recursos e serviços de acessibilidade aos alunos com deficiência. O texto da PEE-SC ao evidenciar a proposta da educação inclusiva, afirma utilizar-se de conceitos e serviços para a educação especial que vão ao encontro da Política de Especial na Perspectiva da Educação Inclusiva (2008).

Palavras-chave: Política de Educação Especial; Atendimento educacional especializado; Santa Catarina.

* Doutoranda pela Universidade do Vale do Itajaí, Itajaí, Santa Catarina, Brasil. 


\section{Policy of special education and the educational service specialist in Santa Catarina state}

\section{Abstract}

The Special Education Policy in Perspective of Inclusive Education (2008) has manifested in the documents that guide inclusive education in the Brazilian states in different ways. In this sense, this article aims to identify the expressions of Special Education Policy in Perspective of Inclusive Education (2008) in Special Education Policy SC (2009), regarding the Educational Service Specialist (ESA). Qualitative approach, document analysis that takes as its data source documents that guide inclusive education at international, national and state level was used. It was found that the Special Education Policy SC to establish the Educational Service Specialist (SAEDE), even with different name, has similarity with the ESA to aim and target audience. The Special Education Policy SC in your text shows the proposed effective inclusive education, where special education is no longer a parallel system with assistencialist approach and becomes a modality that permeates all levels, stages and types of education without replacing them, offering the features and accessibility of services to students with disabilities. The text of the PEE-SC to highlight the proposal of inclusive education, states use to concepts and services for special education to meet the Special Policy in Perspective of Inclusive Education (2008).

Keywords: Special Education policy; Specialized educational service; Santa Catarina.

\section{Introdução}

O direito à educaçáo para todos tem sido um dos principais temas de discussão nas últimas décadas. Discussôes sobre a temática no Brasil emergiram após a Declaração dos Direitos Humanos em 1948, que foi promulgada pela Organizaçáo das Naçóes Unidas (ONU), cujos princípios se pautavam na igualdade, liberdade e fraternidade. O Brasil pautado nos princípios de igualdade anunciados na Declaração dos Direitos Humanos (1948) promulgou em 1988, a Constituição Federal, que passou a assegurar direitos e garantias. Mediante direitos e garantias, a CF/1988 em seu artigo 205, assegura a educação como direito de todos, e, no artigo 206 e 208, estabelece igualdade de condiçôes de acesso e permanência na escola, sendo dever do Estado garantir a oferta do Atendimento Educacional Especializado (AEE), preferencialmente na rede regular de ensino (BRASIL, 1988). Os direitos e garantias contidos na $\mathrm{CF} / 1988$ são decorrentes de ampla discussão nacional e da influência de inúmeros movimentos sociais.

$\mathrm{Na}$ década de 90 ocorreram movimentos internacionais, que tinham como slogan "A Educação para Todos", como a Declaração Mundial de Educação para Todos (1990) e a Declaração de Salamanca (1994), que proclamaram a necessidade de criação de políticas públicas educacionais direcionadas à igualdade de oportunidades. Os princípios desses acordos começam a ser incorporados à legislação brasileira, a 
partir da Lei de Diretrizes e Bases da Educação Nacional (LDBEN no 9.394/96) e nas resoluçôes, pareceres e decretos que decorreram dessa lei. Assim, considera-se que a partir da década de 90, inúmeras mudanças legais e conceituais, assentadas na defesa ao direito de todos à educaçáo, começam a ser elaboradas pela via de programas e políticas educacionais.

Sob a influência dos movimentos internacionais ancorados na "Educação para Todos", o Brasil instituiu uma ampla reforma na Educação. Na reforma educacional, a educaçâo especial foi contemplada como uma possibilidade de democratização do ensino. A Educação Especial, prevista na CF/1988 é regulamentada pela LDBEN no 9.394/96, sendo definida como modalidade de ensino a ser ofertada, preferencialmente, na rede regular de ensino aos alunos com deficiência (BRASIL, 1996). Após doze anos, a Política de Educação Especial na Perspectiva da Educaçáo Inclusiva (2008), reafirma o proposto pela LDBEN no. 9.394/96, ou seja, a educação especial deverá deixar de ser paralela ao ensino comum e passa a transversalizar todos os níveis, etapas e modalidades de ensino, disponibilizando recursos e serviços e realizando o AEE, complementar e/ou suplementar à formação escolar dos alunos com deficiência, transtornos globais do desenvolvimento e altas habilidades/superdotação matriculados na rede regular de ensino (BRASIL, 2008).

Mediante a esse conjunto de ações políticas relacionadas ao direito à Educação para Todos, Pietro (2008) ressalta que as políticas globais influenciam nas decisóes locais dos diferentes âmbitos. Nesta perspectiva, entende-se que há necessidade de pesquisas que objetivem analisar os processos micropolíticos em nível local e a articulação entre os processos macro e micro na construção da política. Para tanto, torna-se necessário embasar-se em um referencial analítico como, a Abordagem do Ciclo de Políticas -ACP (Policy Cyrcle Approach) proposta por Stephen Ball e Richard Bowe, a qual, segundo Mainardes (2006,p. 49) "destaca a natureza complexa e controversa da política educacional, enfatiza os processos micropolíticos e a ação dos profissionais que lidam com as políticas no nível local e indica a necessidade de se articularem os processos macro e micro na análise de políticas educacionais".

Mediante a Abordagem do Ciclo de Políticas tem-se como objetivo identificar as expressôes da Política de Educação Especial na Perspectiva da Educação Inclusiva (2008) na Política de Educação Especial de SC (2009), no que tange o AEE. Para tanto, o artigo encontra-se dividido em três seçóes principais. Na primeira, apresenta-se a metodologia da pesquisa apoiada na ACP, formulado por Stephen Ball e Richard Bowe (1992) a qual se torna determinante para a compreensão das políticas. $\mathrm{Na}$ segunda seção apresenta-se a compreensão do processo de formulação da Política de Educação Especial no contexto da influência e da produção do texto na esfera federal, que resultou na organização do AEE no Estado de SC e na terceira seção as consideraçóes finais.

\section{Metodologia}

De abordagem qualitativa, foi utilizada a análise documental em que toma como fonte de dados os documentos internacionais, sendo eles, a Declaraçáo Uni- 
versal dos Direitos Humanos (1948); Declaração de Salamanca (1994) e Convenção Internacional de Direitos das Pessoas com Deficiência (2006).

Em âmbito nacional, forma utilizados os textos que retrataram os movimentos históricos da Educação Especial no Brasil, especificamente os que discorrem sobre a efetivação do AEE. Dentre eles estão: CF/1998; a LDBEN no 9.394/96 e a PNEE (2008). Nos documentos Estaduais utilizou-se a Política de Educação Especial de SC (2009) e o Programa Pedagógico (2009).

Para a análise dos referidos documentos foi utilizado como principal referencial teórico a "Abordagem do Ciclo de Políticas"de Stephen J. Ball e Richard Bowe (1992). De acordo com esses pesquisadores, a ACP é composta por três contextos principais: contexto de influência, contexto da produçáo do texto e contexto da prática.

O primeiro contexto é o de influência, etapa na qual as políticas são iniciadas e onde são construídos os discursos políticos. Entram em cena diferentes grupos de interesse, com o intuito de influenciar nas definiçôes sociais da educação. É neste contexto "que os conceitos adquirem legitimidade e formam um discurso de base para a política” (MAINARDES, 2006, p. 97).

O segundo contexto refere-se ao de produção de texto. Vinculado ao primeiro, o contexto de produçấo de texto diz respeito aos textos políticos voltados ao interesse do público em geral. A política é representada por esses textos, podendo tomar formas variadas, como textos legais oficiais, comentários formais ou informais, pronunciamentos oficiais, entre outras.

Pautados por embates, disputas e acordos, os textos políticos acabam repercutindo no contexto da prática, onde a "política está sujeita a interpretação e recriação e onde a política produz efeitos e consequências que podem representar mudanças e transformaçôes significativas na política original” (BOWE; BALL, 1992, apud MAINARDES, 2006, p.53).

No Brasil, a ACP, vem sendo discutida pelo pesquisador Jeferson Mainardes (2006, 2009). Segundo Mainardes (2006, p. 49), essa "abordagem destaca a natureza complexa e controversa da política educacional, enfatiza os processos micropolíticos e a ação dos profissionais que lidam com as políticas no nível local e indica a necessidade de se articularem os processos macro e micro na análise de políticas educacionais". Pautada nas palavras de Mainardes (2006), justifica-se a escolha desse referencial, por compreender que o mesmo possibilitará transitar pelos diferentes contextos pelos quais a política é concebida, problematizando e conhecendo as relaçóes que a permeiam desde a sua concepção. Cabe destacar que o breve exercício de análise das políticas ocorreu mediante dois contextos: o contexto da influência e o contexto da produção do texto. 


\section{Educação especial no Brasil: no contexto de influência e da produção do texto}

A inclusão tem sido um dos principais temas de discussão no âmbito nacional e internacional. Porém as discussóes sobre a temática não são recentes. As discussões sobre a inclusão iniciaram com a Declaração dos Direitos Humanos em 1948, que foi promulgada pela ONU, cujos princípios se pautavam na igualdade, liberdade e fraternidade.

Os princípios de igualdade anunciados na Declaração dos Direitos Humanos (1948) foram incorporados na CF/1988, assegurando direitos e garantias. A CF/1988 em seu artigo 205 passa a assegurar a educação como direito de todos, e, no artigo 206, estabelece igualdade de condiçốes de acesso e permanência na escola, sendo dever do Estado garantir a oferta do AEE, preferencialmente na rede regular de ensino (BRASIL, 1988). Avanços com base na referida Constituição ocorreram a partir de 1989, com a Lei n. 7.853/89, que em seu art. 2o, assegurou às pessoas com deficiência "o pleno exercício de seus direitos básicos, inclusive dos direitos à educação, à saúde, ao trabalho, ao lazer, à previdência social, ao amparo à infância e de outros que [...] propiciem seu bem-estar pessoal, social e econômico". (BRASIL, 1989)

Apesar das garantias estabelecidas na CF/1988 e asseguradas a partir da Lei n. 7.853/89, o movimento da inclusão ganhou força na área da educação a partir das reformas educacionais, influenciadas por grandes mudanças políticas e sociais. As mudanças políticas e sociais desencadearam a consolidação dos princípios neoliberais. Com a consolidação dos princípios neoliberais ${ }^{1}$ abriram-se portas para as relações de interesse entre grupos nacionais e internacionais, que passaram a conduzir os processos de controle de mercado, trabalho e produção em todas as esferas sociais. Nesse contexto, o discurso da inclusão tem se constituído como elemento de ordem nas agendas das políticas públicas, sendo interpretada por diversos grupos de interesse.

No que concerne os grupos de interesse, cabe destacar que em 1990 ocorreu a Conferência Mundial em Jontiem, na Tailândia, que contou com patrocinadores como a UNESCO, o Programa das Nações Unidas para o desenvolvimento (PNUD), o Fundo das Nações Unidas para Infância (UNICEF) e o Banco Mundial. Nesta Conferência foi aprovada a Declaração Mundial sobre a Educação para Todos, cujo objetivo, segundo Haddad e Di Pierro (2000) foi o de "repensar" a educação em nível internacional e nacional. $\mathrm{Na}$ junção destes grupos de interesse, destaca-se o contexto de influência, que segundo Mainardes (2006, p.51) é o contexto onde "[...] os conceitos adquirem legitimidade e formam um discurso de base para a política [...]".

No Contexto de Influência as políticas públicas são iniciadas e os discursos são construídos. É nesse contexto que as redes de relaçôes disputam para influenciar a definição das finalidades sociais das políticas. As redes de relações são compostas por órgãos internacionais, que influenciam os mais variados contextos. Assim, grandes organizaçóes internacionais como o Fundo Monetário Internacional (FMI), Organização para Cooperação e Desenvolvimento (OCDE), Organização das Naçóes Unidas para a Educação, a Ciência e a Cultura (UNESCO) e o Banco Mundial potencializam um discurso pautado na integração, ajuda e cooperação econômica mun- 
dial. "Sáo discursos que nem sempre convergem, mas têm em comum a promessa de inclusão, progresso, desenvolvimento, riqueza, democracia, igualdade e qualidade de vida para todos que se inserirem no mercado e na cultura global" (GARCIA, 2010, p. 447).

Os referidos órgãos internacionais com seus discursos consolidaram o neoliberalismo na área educacional, por meio de reformas educacionais desenvolvidas em larga escala, com homogeneidade nos países, principalmente da América Latina. Para Garcia (2008, p.26) "a consolidaçáo do neoliberalismo ocorre sob a orientação de órgãos internacionais, principalmente o Banco Mundial, UNESCO e CEPAL”. Neste contexto, destaca-se que na década de 90 o Banco Mundial passou a ser articulador, das políticas públicas educacionais de todos os países que apresentavam atrasos em seu desenvolvimento econômico, o qual inclui o Brasil.

O Brasil na década de 90, com o objetivo de honrar o compromisso firmado com as agências internacionais e seguir as orientaçôes, fomenta políticas inclusivas. No fomento destas políticas, destaca-se a produção do texto. Cabe destacar que o contexto da produção do texto está interligado com o contexto de influência, pois "o contexto de influência está, usualmente, ligado com determinados interesses e ideologias e o contexto da produção de texto está ligado com "a linguagem do interesse do público mais geral" (MAINARDES, 2006, p. 52)”.

No contexto de influência e de produção do texto, o Brasil elaborou, por meio do Ministério da Educação e do Desporto, o Plano Decenal de Educaçáo para Todos-1993. O referido texto teve como objetivo "assegurar, até o ano 2003, a crianças, jovens e adultos, conteúdos mínimos de aprendizagem que atendam a necessidades elementares da vida contemporânea. " (BRASIL, 1993, p.12-13). Frente ao objetivo do Plano, nota-se que não há clareza sobre quais são as "necessidades elementares da vida" dando margem para diversas interpretaçóes. Nesse sentido, Mainardes (2006, p.52) destaca que os "[...] textos não são necessariamente coerentes e claros e podem também ser contraditórios. Eles podem usar os termos chave de modo diverso".

Um ano após a elaboração do Plano Decenal, ocorreu a "Conferência Mundial sobre Necessidades Educativas Especiais: acesso e qualidade”, realizada pela UNESCO em 1994, da qual resultou a Declaração de Salamanca (1994). A referida Declaração objetivou sustentar o processo de inclusão de todas as crianças nas escolas e apontar possíveis reformas do sistema educacional. Frente as Conferências Internacionais e o fomento de políticas inclusivas no Brasil, cabe destacar que a década de 90,

\begin{abstract}
caracterizou-se como um período de reformas quer seja no âmbito do Estado ou na especificidade da área da Educaçáo, considerada naquele contexto como campo privilegiado para a manutençáo das relaçóes sociais. Tais reformas atingem todos os setores da educação, dentre eles, a Educação Especial. [...]. (GARCIA; MICHELS, 2011, p.106).
\end{abstract}

Sob o contexto de influência das Conferências Internacionais, o Brasil instituiu uma ampla reforma na Educaçáo. Na reforma educacional, textos foram produzidos. Nestes textos a educaçáo especial foi contemplada como uma possibilidade 
de democratização do ensino. A Educação Especial, prevista na CF/1988 é regulamentada pela LDBEN no 9.394/96, no Capítulo V, em que passou a defini-la como modalidade da educação que perpassa todos os níveis de ensino e deve ser oferecida preferencialmente na rede regular de ensino. Além disso, os sistemas de ensino foram orientados a assegurar currículos, métodos e profissionais para atender às necessidades desse público.

Para regulamentar o Capítulo V da LDBEN no 9.394/96, em 2001, foi promulgada a Resolução no 02 do Conselho Nacional de Educação - CNE/CEB 02/2001, que instituiu as Diretrizes Nacionais para Educação Especial na Educação Básica:

Art. $1^{\circ}$ A presente Resolução institui as Diretrizes Nacionais para a educação de alunos que apresentem necessidades educacionais especiais, na Educaçấo Básica, em todas as suas etapas e modalidades.

Parágrafo único. $\mathrm{O}$ atendimento escolar desses alunos terá início na educação infantil, nas creches e pré-escolas, assegurando-lhes os serviços de educação especial sempre que se evidencie, mediante avaliação e interaçáo com a família e a comunidade, a necessidade de atendimento educacional especializado.

A referida resolução em seu artigo $2^{\circ}$ menciona que: "Os sistemas de ensino devem matricular todos os alunos, cabendo às escolas organizarem-se para o atendimento aos alunos com necessidades educacionais especiais, assegurando as condições necessárias para uma educação de qualidade para todos". O artigo da resolução evidencia o proposto no texto da Declaração de Salamanca (1994), em que "[...] o compromisso para com a Educação para Todos, reconhece a necessidade e urgência do providenciamento de educação para as crianças, jovens e adultos com necessidades educacionais especiais dentro do sistema regular de ensino".

Com a necessidade e urgência da inclusão afirmada no texto da Declaração de Salamanca (1994), o Brasil, por meio do MEC/SEESP implantou em 2004, o Programa Educação Inclusiva: direito à diversidade, tendo "[...] por objetivo compartilhar novos conceitos, informaçôes e metodologias - no âmbito da gestão e também da relação pedagógica em todos os estados brasileiros" (BRASIL, 2004, p. 3). Neste mesmo ano, a Procuradoria Federal de Defesa dos Direitos do Cidadão publica o documento: "O acesso de pessoas com deficiência às classes e escolas comuns da rede regular" rediscutindo os preceitos constitucionais e as diretrizes da Lei no. 9.394/96, reforçando o preceito de que o acesso à escola é direito de todas as crianças e adolescentes; que a escola não pode ser adjetivada de especial e que o ensino fundamental não pode ser substituído.

No contexto das reformas educacionais brasileiras impulsionadas pelo âmbito internacional, cabe destacar que as iniciativas voltadas para a pessoa com deficiência foram intensificadas a partir dos compromissos assumidos na Convenção sobre os Direitos da Pessoa com Deficiência - ONU (2006), ratificada pelo Decreto no 6.949/2009 (BRASIL, 2009). A partir da convenção Internacional, o governo 
brasileiro nomeou uma comissão de profissionais da área da educação especial para discutir e elaborar o texto da Política Nacional de Educação Especial na Perspectiva da Educação Inclusiva (BRASIL, 2008). A comissão realizou várias discussões e entregou o texto em 2008. O documento:

\begin{abstract}
objetiva o acesso, a participação e a aprendizagem dos alunos com deficiência, transtornos globais do desenvolvimento e altas habilidades/superdotação nas escolas regulares, orientando os sistemas de ensino para promover respostas às necessidades educacionais especiais, garantindo:

-Transversalidade da educação especial desde a educação infantil até a educação superior; [...] (BRASIL, 2008, p. 8)
\end{abstract}

A referida Política ancorada na Lei no. 9.394/96 afirma que educaçáo especial deve transversalizar todos os níveis, etapas e modalidades de ensino, disponibilizando recursos e o AEE, para complementar e/ou suplementar a formação escolar dos alunos com deficiência, transtornos globais do desenvolvimento e altas habilidades/ superdotação matriculados na rede regular de ensino (BRASIL, 2008). Sobre o AEE, o Decreto no 7.611/11, em substituição ao Decreto no 6.571, dispóe sobre a Educação Especial e o AEE, determinando em seu Artigo $1^{\circ}$ que o sistema educacional seja inclusivo em todos os níveis.

Art. $1^{\circ} \mathrm{O}$ dever do Estado com a educação das pessoas público-alvo da Educação Especial será efetivado de acordo com as seguintes diretrizes:

I - garantia de um sistema educacional inclusivo em todos os níveis, sem discriminação e com base na igualdade de oportunidades;

II - aprendizado ao longo de toda a vida;

III - não exclusão do sistema educacional geral sob alegação de deficiência;

IV - garantia de ensino fundamental gratuito e compulsório, asseguradas adaptaçóes razoáveis de acordo com as necessidades individuais;

V - oferta de apoio necessário, no âmbito do sistema educacional geral, com vistas a facilitar sua efetiva educação;

VI - adoção de medidas de apoio individualizadas e efetivas, em ambientes que maximizem o desenvolvimento acadêmico e social, de acordo com a meta de inclusão plena;

VII - oferta de Educação Especial preferencialmente na rede regular de ensino

A PNEE (2008) ao evidenciar a educação especial com atuação do AEE, destaca que o atendimento deve ser ofertado no turno inverso ao da escolarizaçáo, tendo “[...] como função identificar, elaborar e organizar recursos pedagógicos e de acessibilidade que eliminem as barreiras para a plena participação dos alunos, considerando suas necessidades especificas" (BRASIL, 2008). A Política ainda recomenda que o 
atendimento seja desenvolvido com atividades diferentes daquelas realizadas nas classes comuns, buscando complementar e suplementar "[...] a formação dos alunos com vistas à autonomia e independência na escola e fora dela” (BRASIL, 2008).

Compreende-se que a Educação Especial como transversal e articulada ao ensino comum, mencionada na PNEE (BRASIL, 2008) emergiu na tentativa de superar o paralelismo ao ensino comum, resultando na matricula da pessoa com deficiência em sala de aula comum, acompanhada pelo AEE, na forma de salas de recurso multifuncionais. (SRMs).

Frente aos textos nacionais que representam a política inclusiva, cabe destacar, que estes são resultados de influências e acordos internacionais

\section{Política de educação especial em Santa Catarina e o atendimento educacional especializado}

Partindo da Política Nacional da Educação Especial na Perspectiva da Educação Inclusiva (2008), discorre-se sobre a Educação Especial no Estado de SC, no que tange o AEE.

O Estado de SC, com a intenção de efetivar a educação inclusiva e seguir as orientaçóes nacionais que são pautadas nas internacionais, no ano de 2006, por meio da Secretaria de Educação do Estado (SED) e Fundação Catarinense de Educação Especial $(\mathrm{FCEE})^{2}$ com base nos preceitos legais, institui o documento que define a Política de Educação Especial do Estado. A PEE do Estado é respaldada em âmbito nacional pela "CF/1988; pela Lei no 8.069, que dispóe sobre o Estatuto da Criança e do Adolescente (1990); pela Lei no 9.394/96 e pela Resoluçáo no 02 do CNE/CEB 02/2001." (SANTA CATARINA, 2006a, p. 10).

Após sua elaboração, a referida Política foi ratificada e aprovada pelo Conselho Estadual de Educação (CEE), instituída pela Resolução no.112/2006 (SANTA CATARINA, 2006b). A referida Resolução aponta para a adoção de uma perspectiva ligada à educação inclusiva, apropriando-se de conceitos e ações propostas em âmbito nacional, conforme aponta em seu artigo $1^{\circ}$ :

\footnotetext{
A Educação Especial integra o Sistema Estadual de Educação de Santa de Catarina, caracterizada como modalidade que demanda um conjunto de procedimentos e recursos específicos que visam ao ensino, à prevenção, à reabilitação e à profissionalização da pessoa com deficiência, condutas típicas e altas habilidades (SANTA CATARINA, 2006b).
}

Nessa perspectiva a educação especial é concebida como uma modalidade transversal aos níveis de ensino, etapas e modalidades da educação básica, organizada para apoiar, complementar e suplementar a aprendizagem dos alunos com deficiência. Em SC a proposta se materializa com a implantação de serviços que se encontram nos documentos construídos pela FCEE em parceria com a SED, que demonstram aproximaçáo com os documentos nacionais, sendo eles: a Política de Educaçáo Especial do Estado de SC (2006) e o Programa Pedagógico ${ }^{3}$ (2009). A PEE- SC, apro- 
vada em 2006 pelo Conselho Deliberativo da FCEE, passou por uma atualizaçáo conceitual quando editada e publicada em 2009, tendo como referências as diretrizes da PNEE (BRASIL, 2008) e da Convenção sobre os Direitos da Pessoa com Deficiência - ONU (2006), ratificada pelo Decreto no 6.949/2009 (BRASIL, 2009). Cabe destacar que o Estado de SC atualizou a PEE em 2009, com base nas Convençóes Internacionais e documentos nacionais resultantes da mesma convenção.

$\mathrm{Na}$ atualização da PEE, se mantiveram alguns serviços e instituíram-se novas diretrizes, sendo elas: a) Público: estudantes com diagnóstico de deficiência, transtorno global do desenvolvimento, transtorno do déficit de atenção e hiperatividade e altas habilidades/superdotação; b) Serviço de Atendimento Especializado (SAESP); c) Serviço de Atendimento Educacional Especializado (SAEDE), com caráter complementar ou suplementar, disponibilizado nas suas especificidades; d) Atendimento em Classe: profissionais da educação especial atendendo concomitantemente a frequência do estudante na rede regular de ensino (segundo professor de turma, professor intérprete, instrutor de Libras, professor guia intérprete, professor bilíngue e segundo professor bilíngue).(SANTA CATARINA, 2009).

No que tange o Serviço de Atendimento Educacional Especializado (SAEDE), o documento Programa Pedagógico (2009), destaca suas funções e suas especificidades. Segundo o Programa Pedagógico (2009), o atendimento, foi criado para substituir "[...] as Salas de Recursos e os Serviços de Apoio Pedagógico que foram redimensionados e renomeados, passando a ser denominados de Serviço de Atendimento Educacional Especializado- SAEDE, em sua especificaçáo pela área de atendimento.” (SANTA CATARINA, 2009, p. 24). Com a prerrogativa de um novo serviço, "o SAEDE foi designado por área de deficiência, com caráter complementar ou suplementar, implantados na rede regular de ensino [...]". (SANTA CATARINA, 2009, p. 6).

No contexto da função do SAEDE, Ferreira (2011) e Sachinsku (2013) ressaltam que é perceptível semelhança na caracterização da função do serviço com o AEE, proposto na PNEE (BRASIL, 2008). A semelhança entre os serviços se encontra na Resolução n. 04/2009 (BRASIL, 2009), em seu artigo 2º onde consta que

o AEE tem como função complementar ou suplementar a formação do aluno por meio da disponibilização de serviços, recursos de acessibilidade e estratégias que eliminem as barreiras para sua plena participaçáo na sociedade e desenvolvimento de sua aprendizagem. (BRASIL, 2009, p.5).

Mediante o objetivo de promover a plena participação, o desenvolvimento e a aprendizagem, para a pessoa com deficiência, o SAEDE no Estado de SC, mantêm quatro atendimentos específicos, a saber: o Serviço de Atendimento Educacional Especializado na área da Deficiência Auditiva (SAEDE/DA) ${ }^{4}$; o Serviço de Atendimento Educacional Especializado na área da Deficiência Mental (SAEDE/DM) ${ }^{5}$;o Serviço de Atendimento Educacional Especializado na área da Deficiência Visual $\left(\right.$ SAEDE DV) ${ }^{6}$ e o Serviço de Atendimento Educacional Especializado na Área de Transtornos Globais do Desenvolvimento (SAEDE/TGD) 7 . 
Outro serviço destacado no Programa Pedagógico (2009) é o atendimento em classe. Este serviço trabalha em paralelo com o SAEDE, sendo caracterizado com a "atuação de um professor da área de Educação Especial em sala de aula ou profissional da área da saúde na escola, para atender os alunos de que trata o Programa Pedagógico matriculados nas etapas e modalidades da educaçáo básica, conforme estas Diretrizes (SANTA CATARINA, 2009). Compreende-se que este serviço vem ao encontro do proposto em âmbito nacional no Decreto 7.611 (BRASIL, 2011), ao prever apoio aos alunos devidamente matriculados no ensino regular.

Ao analisar a PPE-SC observam-se expressōes da PNEE (2008). A PEE-SC ao instituir o SAEDE, mesmo com denominação diferenciada, apresenta similaridade com o AEE no objetivo e no público-alvo. A PPE-SC em consonância com a PNEE traz em seu texto a proposta de efetivação da educação inclusiva, em que a Educação Especial deixa de ser um sistema paralelo com abordagem assistencialista e passa a ser uma modalidade que perpassa todos os níveis, etapas e modalidades de ensino, sem substituí-los, ofertando os recursos e serviços de acessibilidade aos alunos com deficiência.

\section{Considerações finais}

O artigo buscou identificar as expressóes da PNEE (2008) na PEE- SC (2009), no que tange AEE. No processo de identificação das expressóes da PNEE (2008) na PEE (2009) buscou-se compreender a Educaçáo Especial no Brasil no contexto de influência e no contexto da produção do texto. No contexto de influência destacouse a emergência do discurso da inclusão, considerando o cenário político e econômico e a influência de órgãos internacionais. Nesse processo observou-se que as PEE no Brasil decorreram das convençóes internacionais, que determinaram o movimento de formulação de políticas inclusivas no âmbito nacional. No movimento de fomento de políticas, destacou-se o contexto da produção do texto, onde foram apresentados alguns textos políticos-normativos, que foram influenciados por grupos de interesses específicos. Nesse contexto observou-se que as políticas são reinterpretadas e resignificadas nos textos políticos locais.

No contexto da produção dos textos políticos locais, especificamente do Estado de SC identificaram-se expressóes da PNEE (2008) na PEE-SC (2009), no que tange a organizaçáo do SAEDE. A PEE-SC ao instituir o SAEDE, mesmo com denominação diferenciada, apresenta similaridade com o AEE no objetivo e no público -alvo. A PEE-SC em seu texto evidencia a proposta de efetivação da educação inclusiva, em que a Educação Especial deixa de ser um sistema paralelo com abordagem assistencialista e passa a ser uma modalidade que perpassa todos os níveis, etapas e modalidades de ensino, sem substituí-los, ofertando os recursos e serviços de acessibilidade aos alunos com deficiência. O texto da PEE-SC ao evidenciar a proposta da educação inclusiva, afirma utilizar-se de conceitos e serviços para a educação especial que vão ao encontro da PNEE (2008). 


\section{Referências}

BALL, S. J.; BOWE, R. et al. Reforming education and changing schools: casestudies in policy sociology. London: Routledge, 1992.

BALL, Stephen J. Global Education INC: new policy networks and the neo-liberal Imaginary. Routledge: London and New York, 2012.

BRASIL. Constituição da República Federativa do Brasil. Brasília; Imprensa Oficial, 1988.

BRASIL. Lei no 7.853, de 24 de outubro de 1989. Dispóe sobre o apoio às pessoas portadoras de deficiência, sua integração social. Brasília, 1989.

BRASIL. Plano Decenal de Educação para Todos. Brasília, 1993.

BRASIL. Declaraçáo de Salamanca e linha de açáo sobre necessidades educativas especiais. Brasília: UNESCO, 1994.

BRASIL. Lei no. 9.394, de dezembro de 1996. Lei de Diretrizes e Bases da Educação Nacional. Brasília: MEC, 1996.

BRASIL. Conselho Nacional de Educação. Câmara de Educaçâao Básica. Resoluçáo no 2, de 11 de setembro de 2001. Diretrizes nacionais para a educação especial na educação básica. Brasília, 2001.

BRASIL. Ministério da Educação. Secretaria de Educação Especial. Programa Educação Inclusiva Direito à Diversidade. MEC/SEESP. Brasília; 2004.

BRASIL. ONU. Convençáo sobre os Direitos das Pessoas com Deficiência. 29 de agosto de 2006. Brasília: 2006.

BRASIL. Ministério da Educação. Secretaria de Educação Especial. Política Nacional de Educaçáo Especial na Perspectiva da Educaçáo Inclusiva. Brasília: MEC/SEESP, 2008.

BRASIL.Institui diretrizes operacionais para o atendimento educacional especializado na educaçáo básica, modalidade educaçáo especial. Brasília, 2009.

BRASIL. Decreto no 7.611, de 17 de novembro de 2011. Dispóe sobre a educaçăo especial e o atendimento educacional especializado. Brasília, 2011.

FERREIRA, S. M. Análise da política do estado de Santa Catarina para a Educaçáo Especial por intermédio dos serviços: o velho travestido de novo? 2011. 246 f. Dissertaçáo (Mestrado em Educação) - Universidade Federal de Santa Catarina, Florianópolis, 2011.

GARCIA, Maria Manuela. Políticas educacionais contemporâneas: tecnologias, imaginários e regimes éticos. Revista Brasileira de Educaçáo, v. 15, n. 45, set./dez., 135 .2010. Disponível em: <http://www.scielo.br/pdf/ rbedu/v15n45/04.pdf>. Acesso em: 22 março 2016.

GARCIA, R. M. C; MICHELIS, M. H. A política de educação especial no Brasil (1991-2011): uma análise da produção do GT15 - educação especial da ANPED. Rev. bras. educ. Espec. vol 7 no. spe1 Marília may -Aug. 2011.

HADDAD, S. Educaçáo de jovens e adultos no Brasil (1986-1998). Brasília: MEC/INEP/Comped, 2000.

HADDAD, S. A ação de governos locais na educação de jovens e adultos. In: Revista Brasileira de educaçáo. Anped, vol. 12, n. 35, p. 197-211, mai./ago. 2007.

MAINARDES, J. Abordagem do ciclo de políticas: uma contribuição para a análise de políticas educacionais. Educ. Soc. Campinas, vol. 27, n 94, p. 47-69, jan./abr. 2006.

MAINARDES, J. Análise de políticas educacionais: breves consideraçôes teórico metodológicas. Contrapontos. Itajaí, vol. 9, n1, p. 4-16, jan./abr., 2009.

PIETRO, R. G. A construçâo de políticas públicas de educaçâo para todos. In: Palhares, M.; MARTINS, S.C. F. (Org). Escola inclusiva. São Carlos: Ed. Da UFSCar, 2008.

SANTA CATARINA. Secretaria de Estado da Educação, Ciência e Tecnologia. Fundação Catarinense de Educação Especial. Política de educação especial no estado de Santa Catarina. São José: FCEE, 2006a.

SANTA CATARINA. Conselho Estadual de Educaçấo. Resoluçáo 112, de 12 de dezembro de 2006. Fixa normas para a educação especial no sistema estadual de educação de Santa Catarina. Florianópolis, 2006b.

SANTA CATARINA. Secretaria de Estado da Educação. Fundação Catarinense de Educação Especial. Programa pedagógico. São José, SC: FCEE, 2009. 
SACHINSKU, I. A política de educaçấo especial nos estados do Paraná e de Santa Catarina: diferentes, mas não divergentes. Dissertação (Mestrado em Educação). Universidade Federal de SC - Florianópolis, 2013.

UNESCO. Declaraçáo Mundial sobre educaçáo para todos: plano de ação para satisfazer as necessidades básicas de aprendizagem. Jomtien, 1990.

UNESCO. Declaraçáo de Salamanca sobre princípios, políticas e prática em educaçáo especial. Espanha, 1994.

\section{Notas}

${ }^{1}$ Segundo Ball (1998, p. 126), o neoliberalismo "é aquilo que se poderia chamar de ideologias de mercado", ou seja, uma proposta vinda do liberalismo que se tornou "neo" por focalizar sua atenção nos aspectos econômicos das propostas liberais.

${ }^{2}$ A área de educação especial do estado conta com a Fundação Catarinense de Educação Especial, cuja função é definir, coordenar e executar a política de educação especial em Santa Catarina. (SACHINSKU, 2013, P.142).

${ }^{3}$ O Programa Pedagógico, dinamizado por meio de açōes e projetos, estabelece diretrizes para qualificar o processo ensino e aprendizagem dos alunos da educação especial matriculados na rede regular de ensino, [...]. (SANTA CATARINA, 2009, p.09-10).

${ }^{4}$ Tem por finalidade "promover a comunicação e a educação da pessoa surda e do deficiente auditivo, contribuindo, assim, para a eliminaçáo das barreiras de comunicaçáo entre surdos e ouvintes e favorecendo a permanência desses alunos no sistema regular de ensino.” (SANTA CATARINA, 2009, p 30.).

${ }^{5}$ Direcionado a pessoa com diagnóstico de deficiência mental, objetiva "qualificar a estrutura do pensamento para a qualificação das funçóes psicológicas superiores, através de metodologias, estratégias e recursos pedagógicos, que possibilitem a apropriação de conhecimento científico.” (SANTA CATARINA, 2009, p 32.).

${ }^{6}$ Direcionado aos alunos com deficiência visual, "caracterizado por um conjunto de procedimentos diferenciados voltados à estimulação de sentidos remanescentes mediante a utilização de recursos e instrumentos específicos mediadores do processo de apropriação e produção de conhecimentos. ” (SANTA CATARINA, 2009, p.34.).

7 “[...] objetiva desenvolver as habilidades que estấo defasadas nas áreas da comunicação, interação social, interesses, autonomia visando a para obtenção de avanços no processo de aprendizagem.” (SANTA CATARINA, 2009, p.39).

\section{Correspondência}

Valéria Becher Trentin - Rua: Bernardino João Victorino, no 27. Apartamento 1003. Bairro: Centro. CEP: 88303-090. Itajaí, Santa Catarina, Brasil.

E-mail: valeriatret@yahoo.com.br

Recebido em 18 de abril de 2016

Aprovado em 21 de junho de 2016 
